\title{
Justicia y reparación: las deudas pendientes de la democracia ${ }^{1}$
}

\author{
Valentina Elisa Hernández Segura ${ }^{2}$
}

\section{RESUMEN}

La justicia y la reparación en derechos humanos por terrorismo de Estado es aún, a 46 años del golpe de Estado cívico militar, un tema pendiente, en el que el Estado de Chile no ha logrado responder a las expectativas de las víctimas. Este artículo sintetiza la percepción de personas víctimas de prisión política y tortura, calificados por la Comisión Valech, y las tensiones que emanan de las políticas implementadas, en contraste con las expectativas sostenidas por las víctimas. Para ello se utilizó una metodología cualitativa, con entrevistas semiestructuradas, lo que permitió categorizar la información en las dimensiones abordadas en la investigación.

Dentro de los hallazgos más relevantes se encuentra la reparación condicionada al castigo penal de los responsables, la valoración mayormente negativa de los mecanismos de reparación, la impunidad como una limitante clave para el desarrollo de la reparación y la necesidad de evaluar los procesos reparatorios por parte de los mismos afectados.

Palabras clave: derechos humanos, violación a los derechos humanos, terrorismo de Estado, reparación en derechos humanos

\section{Justice and Reparations: The Pending Debt of Democracy}

\section{ABSTRACT}

Justice and reparations for human rights violations is still a pending topic, even now, 46 years after the state terrorism arising from the civil-military coup détat.

1 Este artículo es fruto de una investigación presentada para obtener el grado de Magíster en Intervención Social. La tesis presentada fue aprobada en 2018 bajo el nombre de "Mecanismos de Reparación Frente a Violaciones a los Derechos Humanos Establecidos por el Estado de Chile: Una Aproximación desde la Percepción de Víctimas de Prisión Política y Tortura Calificados por la Comisión VALECH”.

2 Chilena. Trabajadora Social, Mg. Intervención Social Mención Familia. E-mail: vhernandezs@miucsh.cl 
In spite of demands, the Chilean government has not adequately responded to victims' expectations regarding criminal justice for those responsible for the human rights violations.

This article summarizes the perception of the people who were victim to political imprisonment and torture, qualified by the Valech Report, and tensions generated by the policies implemented in contrast to the expectations held by the victims.

For this purpose, a qualitative methodology with semi-structured interviews was applied. This allowed for the categorization of information on the different aspects addressed in the study.

Among the most important findings are reparations conditioned upon the criminal liability of the culprits, the mostly negative perception on reparation mechanisms, impunity as a key limitation to the development of repairs, and the need for the victims themselves to evaluate the reparation processes.

Keywords: human rights, human rights violations, state terrorism, human rights reparations

\section{Justiça e reparação: as dívidas pendentes da democracia}

\section{RESUMO}

A justiça e a reparação em Direitos Humanos por causa do terrorismo do Estado é ainda, a 46 anos do golpe do Estado Cívico Militar um tema pendente em que o Estado do Chile não conseguiu responder as expectativas das vítimas.

Este artigo sintetiza a percepção das pessoas que foram vítimas de prisão política e tortura qualificada pela comissão Valech e as tensões que emanam das políticas implementadas no contraste as expectativas sustentadas pelas vítimas. Para isso utilizou-se uma metodologia qualitativa com entrevistas semiestruturadas, permitindo categorizar as informações nas dimensões abordadas na pesquisa.

Entre os achados mais relevantes está o reparo condicionado à punição criminal dos responsáveis, a avaliação principalmente negativa dos mecanismos de reparação, a impunidade como uma limitação chave para o desenvolvimento do reparo e a necessidade de avaliar os processos reparatórios por das pessoas afetadas.

Palavras-chave: Direitos Humanos, Violação em direitos, Terrorismo do Estado, Reparação em Direitos Humanos

\section{Introducción}

Chile, influenciado por contextos políticos acontecidos entre 1950 y 1970, como fue la Guerra Fría y la Revolución cubana, fue gestando una corriente de pensamiento con acento en lo so- 
cial y lo político, en la que, además, confluyeron movimientos como la educación popular y la teología y la filosofía de la liberación. Todos estos movimientos, poco a poco, fueron impulsando nuevos modelos para comprender la sociedad chilena, pero, sobre todo, para impulsar cambios que permitieran a sectores populares de la población comprender su realidad con la finalidad de transformarla, todo ello enmarcado en movimientos extensos por todo Latinoamérica, como la insurgencia cubano-soviética en contra de la contrainsurgencia norteamericana. Muchos de estos países venían de dictaduras militares y problemas asociados a éstas, tales como la pobreza y problemas socioeconómicos. Chile no fue ajeno a este contexto y las ideas revolucionarias de izquierda fueron fortaleciéndose teóricamente y en ámbitos de organización política.

Este contexto es el que permite que Salvador Allende Gossens, candidato a la presidencia de Chile por cuatro veces consecutivas, logre la victoria en 1970, siendo un presidente con clara propuesta de transición socialista por vías constitucionales.

Estos hechos generaron controversia en grupos opositores al gobierno y grupos económicos empresariales ligados a la derecha política. Ello hizo que la situación se tornara cada vez más compleja y, finalmente, el 11 de septiembre de 1973 se desencadenó un golpe de Estado cívico-militar que derrocó el gobierno del presidente Allende. Dicha dictadura se mantuvo hasta el 11 de marzo de 1990, periodo durante el cual se instauró un sistema de represión, amenaza y violencia política dentro de las relaciones sociales y la vida cotidiana, manifestándose estas dimensiones como trauma político. "Este trauma implica no solo la ruptura del funcionamiento institucional de la sociedad, sino la introducción de la amenaza política como un factor constituyente de las relaciones sociales bajo condiciones de violencia y terrorismo de Estado" (Lira y Castillo, 1993, p. 99).

Es en este contexto que la dictadura cívico-militar trae consigo violaciones a los derechos humanos, ejercidas de manera siste- 
mática por agentes del Estado. Estas provocaron daño y dolor a quienes las sufrieron directamente, pero también a sus familias y descendientes (Informe de Derechos Humanos para estudiantes, año 2014).

Según el informe elaborado por la Comisión Nacional de Verdad y Reconciliación $(1991)^{3}$, estas violaciones se manifiestan a través de personas detenidas y desaparecidas, lo que se constituye como desaparición forzada, ejecución en cualquiera de sus formas, uso indebido de la fuerza con resultado de muerte, abuso de poder con resultado de muerte, tortura con resultado de muerte, muertes en hora de toque de queda y actos terroristas. Al retornar la democracia, con el gobierno encabezado con el presidente Patricio Aylwin, el Estado de Chile se propone investigar las graves y masivas violaciones a los derechos humanos ocurridas durante la dictadura cívico-militar. Es así como el 9 de mayo de 1990, mediante la publicación del Decreto Supremo $N^{\circ} 355$ del Ministerio del Interior, se crea la Comisión Nacional de Verdad y Reconciliación, conocida como Comisión Rettig, que tuvo como primera iniciativa contribuir al esclarecimiento de la verdad de las violaciones cometidas durante la dictadura, todo esto con el fin de lograr la reconciliación de todos los chilenos. Dicho informe se establece, por tanto, como la piedra angular de la investigación y esclarecimiento de las violaciones acontecidas.

\section{Antecedentes: reparación en derechos humanos por terrorismo de Estado}

Con el retorno a la democracia, el Estado de Chile, a través de diferentes comisiones investigadoras, determinó reconocer y reparar el daño causado por la dictadura cívico-militar; sin embar-

3 La Comisión Nacional de Verdad y Reconciliación fue creada en 1990 con el objetivo de contribuir al esclarecimiento de las principales violaciones a los derechos humanos cometidas entre el 11 de septiembre de 1973 y el 11 de marzo de 1990, trabajo que dio como resultado un informe de tres tomos, que recoge un detalle de cada una de las víctimas de violaciones a los derechos humanos con resultado de muerte. Recuperado de https://bibliotecadigital.indh.cl/handle/123456789/170 
go, las medidas reparatorias establecidas no han sido del todo satisfactorias para las personas que fueron víctima de terrorismos de Estado en sus diferentes grados, niveles y tipificaciones. Lorena Fries (2015), quién fue directora del Instituto Nacional de Derechos Humanos (INDH) desde su conformación hasta 2016, señala las diferencias entre el tratamiento de algunas víctimas de violencia de Estado en relación a otra tipificación, más específicamente entre los calificados por el Informe de la Comisión Nacional de Prisión Política y Tortura (Comisión Valech), creada el año 2003 y cuyo objetivo fue esclarecer la identidad de las personas que sufrieron prisión y torturas por motivos políticos por parte de agentes del Estado de Chile, y las personas calificadas por la Comisión Nacional de Verdad y Reconciliación (Rettig), creada el año 1990, cuya misión fue esclarecer por primera vez las graves violaciones a los derechos humanos cometidas entre el 11 de septiembre de 1973 y el 11 de marzo de 1990, y establecer las nóminas de las personas que fueron detenidas y desaparecidas durante la dictadura.

El 12 de agosto de 2003 se dieron a conocer las propuestas sobre derechos humanos. El presidente de la época, Ricardo Lagos Escobar, partió de la base de que el dolor de quienes fueron detenidos, encarcelados y torturados por razones políticas era inmenso e incalculable, y por tanto este daño debía ser reparado. Para ello decidió crear la Comisión Nacional Sobre Prisión Política y Tortura. En el informe de la Comisión se recogió el testimonio de 35.865 personas, residentes en Chile y en el extranjero, y de ellos alrededor de 28.000 fueron calificados para recibir los beneficios de reparación estipulados (Informe de la Comisión Nacional de Prisión Política y Tortura, 2004).

Teniendo en cuenta los antecedentes planteados, se observa con mayor claridad la relevancia de visibilizar la insatisfacción de las víctimas calificadas por la comisión Valech respecto de los mecanismos implementados por el Estado de Chile, ya que los mecanismos, una vez recuperada la democracia, se orientan desde las 
siguientes dimensiones, según documento de beneficio a favor de calificados Valech.

Tabla beneficio para prisioneros torturados políticos, según Ley 19.992 y sus modificaciones

\begin{tabular}{|c|c|}
\hline Dimensiones & Beneficios \\
\hline Monetaria & $\begin{array}{l}\text { - Pensión anual } \\
\text { - Bono de opción } \\
\text { - Bono a menor de edad }\end{array}$ \\
\hline Médica & $\begin{array}{l}\text { - Derecho a la gratuidad de las prestaciones médicas otorga- } \\
\text { das a través del programa de reparación y atención integral } \\
\text { de salud (Prais) } \\
\text { - Apoyo técnico y rehabilitación física. }\end{array}$ \\
\hline Educacional & $\begin{array}{l}\text { - Continuidad gratuita de estudios (básicos, medios, univer- } \\
\text { sitarios) }\end{array}$ \\
\hline De vivienda & - Acceso a subsidio de vivienda \\
\hline Otras & $\begin{array}{l}\text { - Exención de realizar el servicio militar } \\
\text { - Eliminación de anotaciones prontuariales }\end{array}$ \\
\hline
\end{tabular}

* Elaboración propia, según ley 19.992 que guía los beneficios. Chile: Biblioteca del Congreso Nacional de Chile BCN (2018). Beneficio Para Prisioneros Torturados Políticos.

Recuperado de https://www.bcn.cl/leyfacil/recurso/beneficios-para-prisionerosy-torturados-politicos

Como se aprecia en la tabla anterior, ninguna de las dimensiones expuestas incluye la justicia dentro de sus lineamientos, es decir, la reparación entregada por el Estado de Chile se centra en factores que, si bien son necesarios, no buscan sancionar a los responsables de las violaciones a los derechos humanos ${ }^{4}$.

Con base en lo mencionado, Sergio Reyes, de la Agrupación de Derechos Humanos Salvador Allende, señala:

Las propuestas de "reparación" del presidente buscan cerrar 31 años de angustia con compensación monetaria. Por cierto, hay

4 Siendo en muchos casos, rostros visibles, como por ejemplo el exalcalde de providencia Cristián Labbé, quien fue, además, en periodo de dictadura cívicomilitar, agente de la Dirección de Inteligencia Nacional (DINA). 
que reconocerle que ha hecho más que ninguna de las administraciones post-Pinochet, pero se ha quedado corto. El presidente Aylwin, al conocer el informe Rettig sobre los desaparecidos, derramó lágrimas de cocodrilo, sin reconocer la propia responsabilidad de su Partido Demócrata Cristiano en los hechos. También entonces se dieron algunas compensaciones monetarias, pero no se hizo justicia. Ese informe reconoció alrededor de 3.000 casos de desapariciones por causas políticas. Este informe reconoce 28.000 casos de tortura y prisión política. El gasto será mayor. Pero las instituciones, los responsables, empezando desde la cabeza misma del sistema, el general Augusto Pinochet y los miembros de su Junta Militar salen impunes. (Memoria Colectiva, 2004)

En la cita anterior se evidencia que las propuestas de reparación estatales se centran básicamente en la compensación económica, lo cual es relevante y pertinente, sin embargo, también se visualiza que no se ha hecho justicia. Es posible hablar entonces de la impunidad y de la implicancia que esto tiene para las víctimas y su proceso de reparación.

Este año 2019 se han cumplido veintiocho años desde el retorno a la democracia; sin embargo, la reparación aún tiene aristas no resueltas y que se constituyen como problemas en la actualidad ${ }^{5}$. Lo anterior demuestra la fragilidad con la cual se tratan los casos de los violadores de derechos humanos. Cristián Labbé Toncoso, por ejemplo, fue condenado solo por uno de los tres casos de tortura en que fue enjuiciado. Se señala, además, que no existen antecedentes de su participación en los tres delitos y que, por tanto, se revoca la decisión y se acoge en parte el recurso de amparo presentado por el abogado del excoronel. Por otra parte, es posible considerar estos hechos como una revictimización, ya que, como señalan Bezanilla, Miranda y González (2016), dentro de

5 Así lo demuestra la sala constitucional de la Corte Suprema, al revocar parcialmente el procesamiento del exalcalde Cristian Labbé frente a tres de las cuatro imputaciones de tortura en su contra. 
la atención y acompañamiento psicosocial de personas que han sido víctimas de violencia o violaciones graves a los derechos humanos, un factor de suma importancia de evitar es, justamente, la revictimización, la cual muchas veces se vive a través de una violencia institucional, que se desprende de una violencia estructural mayor. En muchos casos esto se manifiesta en la criminalización de la persona o a través de la culpa. Actualmente, aún es común escuchar personas que señalan que torturados o desaparecidos en dictadura "no eran blancas palomas, o era porque andaban en malos pasos", justificando la atrocidad de los hechos.

Debido a esto, es necesario dar a conocer lo que estas víctimas de prisión política y tortura entienden por reparación, la opinión que tienen de los mecanismos reparatorios establecidos por el Estado y, por último, los desafíos pendientes en esta área y en derechos humanos.

\section{Metodología}

Esta investigación se enmarcó en el paradigma interpretativo, ya que buscó conocer la percepción de las personas víctimas de prisión política y tortura, que fueron calificadas por la Comisión Valech, acerca de los mecanismos de reparación establecidos por el Estado de Chile respecto de sus propios procesos reparatorios. Por esto, se decide optar por una corriente sociológica como el interaccionismo simbólico, que permite la construcción de los significados poniendo énfasis en la comunicación de los sujetos para la comprensión de la sociedad, asignando relevancia a la capacidad de las personas para pensar e interpretar el mundo en el que viven. Además, es de carácter descriptivo, porque especifica las propiedades, características, perfiles y rasgos importantes de las personas que forman parte del fenómeno que se analiza.

Una herramienta principal para el desarrollo de la investigación fue la exploración y recolección de información de fuentes secundarias desde análisis de contenidos y revisión documental. Se utilizó como técnica la entrevista en profundidad, semies- 
tructurada, en la que se realizan consultas con la posibilidad de matizar la entrevista con preguntas abiertas y cerradas, similar a una conversación, sin perder el propósito de conocer la opinión de las personas respecto de un tema específico, proporcionando una mayor participación al entrevistado sobre el tema de investigación.

\section{Resultados}

Los resultados obtenidos son extensos; sin embargo, para efecto de este artículo se han organizado de manera breve, sintetizando los principales resultados de cada categoría de análisis desarrollada. Las dimensiones que se abordarán a continuación son la reparación; opiniones respecto de los mecanismos de reparación; justicia y reparación, y, para finalizar, las deudas pendientes en justicia y reparación en derechos humanos.

\section{Reparación}

La reparación es señalada como una forma de compensación por el daño causado por terrorismo de Estado. Dentro de ello se señalan dimensiones tales como el ámbito económico, sanitario, educacional, simbólico, habitacional y justicia. Los tratos directos de estas dimensiones, a través de los beneficios de reparación, componen la "reparación integral", concepto acuñado por las víctimas. Bajo esta lógica, la reparación debe ser transgeneracional, permanente y garantizada. Se acentúa que no existe reparación del daño sin justicia. La relevancia de la reparación radica en la compensación por lo que ellos, como ciudadanos, entregaron por Chile, un proyecto social y comunitario, pero también vidas truncadas que, al volver a la democracia, fueron imposibles de retomar del mismo modo. Es por ello que se mencionan ciertos componentes que deben tenerse en cuenta para que exista la reparación; estos responden al respeto, verdad, justicia, voluntad política, memoria y su permanencia en el tiempo como componente de cambio y defensa de los derechos humanos, ampliándose al nivel del Estado; estos son los principales componentes mencionados para este fin. 
La definición de "reparación" que se utilizó es la entregada por el Estado de Chile a través de la Comisión Nacional de Verdad y Reconciliación (1991), que expresa lo siguiente:

la Reparación es un conjunto de actos que expresan el reconocimiento y la responsabilidad que le cabe al Estado en los hechos y circunstancias acaecidos durante la dictadura militar, entre el 11 de septiembre de 1973 y el 11 de marzo de 1990, producto de la represión política ejercida por el Estado.

Por lo tanto, cabe destacar que esta definición no está alejada de lo que las personas víctimas de prisión política y tortura manifiestan. Así se señala en la Entrevista n ${ }^{\circ}$ : "Es la culpa que tiene que pagar el Estado de Chile con nosotros... toda la gente debió haber recibido una reparación más que nada por haber sido dañado por agentes del Estado, instituciones del Estado" (Hernández, 2018, p. 70).

Se puede apreciar que se tiene conciencia de quién o quiénes tienen la obligación de reparar el daño, y también las razones que provocaron las violaciones a los derechos humanos. Asimismo, se presentan de forma clara las dimensiones en las cuales quieren ser reparados.

Para mí la reparación en caso de DDHH no significa solamente la reparación económica. Yo creo que la cosa era haber hecho justicia clara con la gente involucrada, porque en definitiva el problema de la dictadura militar fue fuerte para el pueblo chileno. E2 (Hernández, 2018, p. 69)

De esta manera se expresa un elemento sustancial para pensar la reparación, y es que esta no puede concebirse sin la justicia, expresamente referida a la condena de los responsables de los atropellos a los derechos humanos.

\section{Opiniones respecto de los mecanismos de reparación}

La opinión que expresan los entrevistados respecto de los mecanismos de reparación es negativa. Los valoran como deficientes, 
mal formulados e implementados. Que poco o nada ayudan a que exista la reparación, ya que no se orientan a un proceso, sino a un conjunto de acciones ineficientes que aportan a la revictimización y al aumento de la rabia contra las medidas adoptadas. En este punto, se aspiraba a una reparación como proceso, que incorporara profesionales especializados en temáticas de terrorismo de Estado, duelo y trauma. Otro de los puntos, relacionado con las expectativas, está vinculado a la calificación de manera permanente, la ampliación de la cobertura de las personas calificadas. El aumento del monto de pensión, al menos igualando a un sueldo mínimo, mayor capacidad de atención en el Programa de Atención y Salud Integral, PRAIS.

Se evidencia en todos los discursos una opinión negativa respecto de los mecanismos de resarcimiento que el Estado de Chile estableció para la reparación del daño. Y esto parte desde la disconformidad con los gobiernos posteriores a la dictadura y que estuvieron a cargo de restablecer la democracia. Se menciona con rabia que se perdió un proyecto social comunitario y amplio, que a su vez fue reemplazado por un individualismo que prima hasta el día de hoy.

Yo creo que las autoridades que ha habido después del golpe hasta ahora, no han dado nunca con lo que quiere el pueblo chileno y lo que Salvador Allende quería, de hacer una gran nación, que la educación fuera gratis, que los niños tuvieran leche desde que nacen y así sus 40 medidas, pero lamentablemente nadie toma eso en cuenta, hoy las reuniones políticas que tenemos siempre sale el tema (...) entonces creo que la organización política de izquierda, llamada de izquierda, no supo conciliar el fondo de esto, nosotros no teníamos armas, no querías dañar a nadie, sino el diálogo y hacer las cosas bien y que se vieran bien hechas, y ahora ya no es así, ahora hay un individualismo a flor de piel... E3 (Hernández, 2018, p. 83)

Más allá del proyecto perdido, se menciona que no hay nada que pueda recuperarse del todo, que no se puede restaurar ni reparar 
lo que el golpe militar significó para algunas personas, y que bajo ese contexto no existe beneficio económico que sirva para la total reparación.

Yo creo que nada puede reponer o restaurar todo lo que significó el golpe militar. O sea, el derecho del pueblo de expresarse, de tener un ideal y de luchar por él. Yo creo que no hay nada que pueda recuperar la vida de la gente que murió combatiendo, y la gente que mataron acusándola de terrorista. Yo creo que nada económico puede reparar eso. E2 (Hernández, 2018, p. 88)

Se evalúan de igual forma ciertos beneficios de reparación entregados, tales como el Programa de Reparación y Atención Integral de Salud (PRAIS), el cual en intención ha sido bien evaluado, no obstante, no cumple con las expectativas de las víctimas en aspectos tales como la cantidad de profesionales versus el número de personas inscritas para atención. "Es pésimo (...) ni la pensión ni la atención de PRAIS, que hoy día es muy mala, es un tema que se debate a nivel de todo el país” E1 (Hernández, 2018, p. 88).

Otro tema es la formación de los profesionales que se encargan de entregar este acompañamiento, colocando como demanda la relevancia de que este sea un equipo profesional especializado en violaciones a los $\mathrm{DDHH}$ y en reparaciones de esta índole, con las particularidades que esto pueda significar.

Bajo este contexto, se refiere además que el Estado no ha respondido a la altura de las expectativas que las víctimas, en su conjunto, sostenían respecto de los mecanismos de reparación. Y, bajo esta misma lógica, sostienen que las autoridades que ha habido después del Golpe de Estado cívico-militar no han logrado dar con lo que las víctimas han querido en cuanto a reparación, señalando que ninguna de estas políticas ha podido mitigar el dolor ni aproximar a las personas a la situación en que estaban antes del Golpe de Estado, tal y como señalaba la Comisión Nacional de Verdad y Reconciliación como parte de sus objetivos principales. "No, para nada, si yo hago mi balance de cuál era mi situación 
económica de esos años, no me han devuelto nada, nada" E3 (Hernández, 2018, p. 89).

La reparación es definida, por parte de las víctimas de prisión política y tortura, como como "débil", "suave" y "leve":

Mira, algo supe de esto. Creo que la presión, no la presión, sino la exigencia de la gente, que se ha mostrado de una u otra forma, se está pidiendo, lo que creo yo, que sea estudiada de una forma más completa. Lo que se hizo con la comisión Valech fue para mí una cosa muy leve, muy suave. Yo creo que no ha sido muy beneficiosa, algo ha podido aliviar ese malestar y eso, pero no fue en realidad lo que se debió haber realizado. E2 (Hernández, 2018, p. 89)

A esta situación desventajosa se suma la indiferencia de las autoridades pertinentes, que no dieron espacios adecuados para escuchar a las personas afectadas, ya sea como contención o como vinculación con las políticas posteriormente implementadas, lo que ellos definen como un daño muy mal tratado.

\section{Justicia y reparación}

La justicia ha sido una de las dimensiones más relevantes al hablar de reparación, ya que la reparación no se concibe sin aplicar justicia a los responsables de las violaciones a los derechos humanos. De esta forma, se establece la impunidad como una limitante para la reparación del daño, pero también se concibe como condicionante para avanzar en materias de derechos humanos. Se afirma que la justicia ha actuado de manera insuficiente, favoreciendo a los criminales y responsables de las violaciones. Por ello, la justicia debe incorporar todas las dimensiones estudiadas para reparar de manera integral, incluyendo en ello la condena de los responsables y el reconocimiento público y legal del daño.

En cuanto a los avances jurídicos y procesamientos, éstos han sido evaluados como deficientes y repudiables, ya que han sido pocos los casos en los cuales se ha formalizado a los culpables y, de ser así, estos tienen beneficios y consideraciones que atentan contra la 
salud y dignidad de las víctimas y por tanto a su proceso de reparación del daño. En esta lógica, se da a conocer que las condiciones ideales para avanzar en justicia son, principalmente, romper con los pactos de silencio, visibilizar la reparación como un problema social que debe tratarse en el parlamento, para así desarrollar un compromiso político transversal a las ideologías de cada sector. Y no más encubrimiento de los responsables, por ciertas élites políticas cercanas a los ideales que la dictadura cívico-militar intento forjar.

Se observa que las personas entrevistadas perciben una sensación de burla con el actuar de la justicia, ya que refieren que los violadores de derechos humanos están protegidos en todos los aspectos, mientras ellos se encuentran en la incertidumbre respecto de sus condiciones de víctimas:

Es una burla, porque tú ves la realidad que le toca al bando perdedor y ves la realidad del bando ganador, ellos van al juzgado en autos bastante buenos y otra serie de detalles, y uno se da cuenta que siempre va a ser así. E4 (Hernández, 2018, p. 96)

Además, se suma la impotencia de la impunidad. Esto conlleva la sensación de que la reparación no existe sin condena y no puede darse sin justicia. Se señala fuertemente que "mientras no haya justicia no habrá reparación”, en tanto no se encuentren los cuerpos de los familiares y mientras no se enjuicie a los responsables de las violaciones a los derechos humanos no se puede llegar a una reparación. Se señala que el perdón es algo que ellos trabajan, pero perdonar no significa eximir a los responsables de sus culpas:

Hay que condenarlos, condenarlos porque hay muchos que hoy en día tienen odio, lo sé, trabajo de taxista y me he encontrado con gente que dice que el tirano Pinochet la embarró porque dejó muchos sueltos, que debería haber matado más, y en la misma conversación uno se da cuenta que son militares jubilados. Eº (Hernández, 2018, p. 98) 


\section{Deudas pendientes en reparación en derechos humanos}

Los desafíos pendientes se relacionan con la demanda de que se cumplan las promesas realizadas con el retorno a la democracia. Esto alude a repensar y mejorar los "beneficios de reparación". El Estado de Chile, al clasificarlos como "beneficios", pone de manifiesto una orientación de sus políticas reparatorias a la par de cualquier otro tema social, negando así la reparación como un derecho con sus especificidades, desplegadas de la complejidad del daño por terrorismo de Estado.

Estos desafíos pendientes también se orientan hacia el avance de la reparación simbólica, a través de los sitios de memoria, que ayuden a contribuir a la construcción de la memoria país, reconocimiento de los hechos y a una reparación que abarca a la sociedad chilena en su conjunto.

Otro de los grandes desafíos se refiere a la educación en derechos humanos, que debiese garantizarse desde la educación primaria hasta la universidad, esto último dependiendo del sello de la carrera escogida, pero manteniendo siempre un enfoque en derechos humanos. Se establece, por tanto, la educación como una herramienta de promoción y difusión de los derechos humanos, a través del reconocimiento del pasado y del conocimiento de los hechos acontecidos.

La responsabilidad de llevar a cabo estos desafíos pendientes se atribuye al Estado de Chile, a través de sus diferentes gobernantes o gobiernos de turno. En cuanto a las proyecciones, en la mayoría existe desconfianza en que la reparación mejore o se resuelvan los puntos mencionados. Aunque se enfatiza que algunos avances son posibles gracias a la política internacional.

Se observa que, a pesar del tiempo transcurrido, aún existen desafíos pendientes en distintas esferas, tales como la vivienda, memoria histórica, pensiones, educación en derechos humanos, entre otros:

Está pendiente la reparación, está pendiente la memoria histórica y está pendiente el tema de salud y todos los temas im- 
plícitos; la vivienda, todo lo que pretendieron implementar no se ha hecho nunca. Tienen que reparar en todas sus formas, en salud, económicamente, vivienda, en todo. $\mathrm{E}^{\circ} 1$ (Hernández, 2018, p. 105)

Todo esto permite reflexionar que los desafíos pendientes abarcan prácticamente todas las líneas de acción que tenía el Estado de Chile a través de los mecanismos reparatorios. Si estas esferas que ya fueron tratadas siguen siendo desafíos, ello significa que estos beneficios de reparación no han sido suficientes, y se condice con la opinión acerca de de dichos mecanismos. "Se nos ha engañado, se nos han prometido cosas y no han cumplido. Creo que, partiendo de esa base, nos están debiendo bastante" E³ (Hernández, 2018, p. 107).

Aún se espera que se repare adecuadamente en temáticas de vivienda, señalando que muchos expresos políticos están viviendo situaciones de extrema vulnerabilidad como consecuencia de la violación a sus derechos humanos.

Que fuera real lo prometido, plan de vivienda. Esta fue una pelea que la ganamos, porque fue política y si a nosotros (Paine) nos salió ¿por qué no otros? Que se creen más memoriales, más y mejor educación en el colegio. $\mathrm{E}^{\circ} 4$ (Hernández, 2018, p. 105)

Pareciera ser que uno de los grandes desafíos pendientes en materia de derechos humanos y reparación, es la educación en estas temáticas y la prohibición del fascismo a través de la Constitución. Los entrevistados refieren que este sería el camino seguro para que en Chile no se vuelvan a cometer atropellos como los ya vividos. De igual manera, sostienen que se debe continuar en caminos de promoción y protección en derechos humanos: "Debiese haber un ramo o asignaturas en derechos humanos, que se hable constantemente del tema” Eº (Hernández, 2018, p. 107).

Yo establecería como norma, la prohibición del fascismo en Chile y lo definiría ideológicamente como hicieron los alemanes con el nazismo, que está prohibido en la Constitución. Yo 
creo que en Chile se amerita eso, creo que debería hacerse una prohibición y establecer políticamente qué es el fascismo y cómo es. Otra cosa, creo que debería haber un centro de la memoria que fuera más importante, debería haber un centro de la memoria, de manera que esto no volviera a pasar. $\mathrm{E}^{\circ} 6$ (Hernández, 2018, p. 106)

Se acentúa la importancia de los centros de recuerdo y su labor con la memoria histórica. Se espera un mayor financiamiento y seguimiento de estos espacios por parte del Estado de Chile, para que continúen funcionando y entregando elementos de historia, política y simbolismos, que se constituyen como riqueza y aprendizaje para la protección de la democracia del país.

\section{Reflexiones finales}

Los hallazgos de este trabajo permiten analizar esta realidad de una manera crítica. Sin embargo, el aporte más significativo, y que valida en gran parte la investigación realizada, radica en que todo el material e información levantada emanan directamente de las víctimas que hacen uso de los mecanismos reparatorios establecidos, lo cual hasta el momento solo se había abordado a través de cifras y/ porcentajes, sin conocer la opinión de las personas a las cuales estas políticas estaban orientadas.

Aclarando lo anterior, se observó que lo primero que surgió fue la noción de "reparación" que mantienen las personas víctimas de prisión política y tortura, calificados por la Comisión Valech, la cual se contrastó con la definición que el Estado de Chile tiene de esta misma noción. Si bien existen similitudes en la definición y en los ámbitos a reparar, las diferencias radican en las formas de implementar las medidas reparatorias, plazos, cobertura y calificación de víctimas. Una de las discrepancias más sustanciales es la visión de la reparación, la que, según el Estado de Chile, se ubica dentro de la categoría de "beneficios reparatorios", mientras que desde la visión de las víctimas son derechos de reparación por terrorismo de Estado. Estos diferentes enfoques conllevan diferen- 
cias en la intervención, implementación de las medidas y reconocimiento social en todo el país.

En cuanto al proceso de reparación, para las víctimas no es posible si no se incorpora la justicia dentro de los procesos. Esto quiere decir que es necesario el procesamiento y condena por los delitos de las violaciones de los derechos humanos, tanto judicialmento como en términos de condena social. La suma de todas estas dimensiones la denominan "reparación integral", y la relevancia de la reparación se define como el daño que debe reparar el Estado de Chile para devolver, en parte, todo lo que ellos entregaron por el país en su dimensión humana, política y ciudadana.

En cuanto a la opinión de los mecanismos de reparación establecidos por el Estado de Chile, se evidencia que son valorados negativamente por estas víctimas. Se percibe la necesidad de dar a conocer que han sido insuficientes y que no han cumplido las expectativas que ellos mantenían al respecto. Algo relevante de mencionar es que las personas involucradas no se han sentido parte del proceso, siendo estas medidas reparatorias pensadas solo desde una visión tecnocrática, sin incorporar sus visiones ni demandas al respecto. Sus expectativas, en general, apuntan a mejorar los mecanismos ya existentes, aumentar coberturas y montos, e incorporar profesionales especializados en temáticas de terrorismo de Estado, duelo, trauma y daño político. En las expectativas, vuelven a surgir los elementos de justicia y memoria como factores primordiales para que exista la reparación integral.

Respecto de la justicia y la reparación, se menciona la impunidad como una de las limitantes claves para el desarrollo de la reparación y, además, se acentúa como responsable de la revictimización y todo el proceso psicológico que esto significa; es decir, el daño, el trauma, el duelo y la proyección al futuro truncada por un pasado aún abierto. Lo anterior alude a que la justicia ha sido inoperante: las condenas a los responsables no han respondido a las expectativas; lo mismo ocurre con los tipos de condena y los sitios de reclu- 
sión. Se menciona que es posible cambiar esta situación mediante la voluntad política, la memoria y la organización de la sociedad civil en estas temáticas.

En cuanto a las deudas pendientes, estas aluden al mejoramiento de los mecanismos de reparación y a la instalación nuevamente de estas temáticas en los escenarios políticos de poder, tales como el Parlamento. Se evidencia la necesidad de evaluar los procesos y de llevar un seguimiento adecuado que permita dar cuenta de los avances. En cuanto a las responsabilidades de llevar a cabo estos desafíos, se responsabiliza mayoritariamente al Estado de Chile a través de sus diferentes gobiernos. Existe una sensación de incredulidad respecto de este proceso, lo que se manifiesta en sensación de desesperanza; no obstante, se muestran firmes en la convicción de la reparación como derecho en el marco del Derecho Internacional y de la Corte Interamericana de Derechos Humanos, como una instancia de apelación para hacer pagar al Estado de Chile por la reparación considerada insatisfactoria.

Es relevante señalar la importancia que tiene este tipo de estudios para el Trabajo Social, disciplina que, históricamente, ha sido permeada por los cambios y que su quehacer por naturaleza está involucrado en los espacios de injusticia y privación. El Trabajo Social tuvo un rol fundamental en la defensa de los derechos humanos en la dictadura cívico-militar, a través de la Vicaria de la Solidaridad ${ }^{6}$, en la que asistentes sociales brindaban acompañamiento de toda índole, soportando condiciones de extrema represión. No solo eso, sino que Trabajo Social fue una carrera vetada en dictadura, cerrada en algunas universidades, y esto nos habla de la naturaleza de la profesión, que promueve el cambio social, demanda las injusticias sociales, se inserta en el tejido social, forja lo comunitario, empodera y organiza. Elementos peligrosos para la dictadura que intentó instalar el terror y la desconfianza en el

6 Para conocer en profundidad sobre este tema, se recomienda la lectura del libro Las Asistentes Sociales de la Vicaría de la Solidaridad, de María Soledad del Villar, editado en el año 2018 por la Universidad Alberto Hurtado. 
pueblo de Chile. Esta investigación es relevante para el Trabajo Social porque los derechos humanos son parte esencial de nuestra disciplina, la piedra angular de la intervención profesional y un desafío ético y político que nos toca asumir a todos los profesionales del área en cada espacio en el cual estemos insertos, con un enfoque en derechos humanos, protegiendo, promoviendo, difundiendo y respetando, para así llegar nuestro fin último: la persona humana y la justicia social.

\section{Bibliografía}

Bezanilla, M., Miranda, M. y González, J. (2016). Violaciones Graves a los Derechos Humanos. Violencia Institucional y Revictimización, 2(15). Recuperado de http://www.cuadernosdecrisis.com/docs/2016/numero15vol2_2016_5violaciones_ graves_ddhh.pdf

Biblioteca del Congreso Nacional de Chile. (2013). Beneficios a Favor de Prisioneros y Torturados políticos COMISIÓN VALECH. Recuperado de http://www.bcn.cl/leyfacil/recurso/beneficios-para-prisioneros-y-torturados-politicos

Comisión Nacional de Verdad y Reconciliación. (1991). Informe de la Comisión Nacional de Verdad y Reconciliación. Tomos 1-3. Santiago de Chile. Recuperado de http://bibliotecadigital.indh.cl/handle/123456789/170

Comisión de Prisión Política y Tortura. (2004). Informe Comisión Nacional de Prisión Política y Tortura Valech I. Santiago de Chile. Recuperado de https://www.bcn.cl/leyfacil/recurso/beneficios-para-prisioneros-y-torturados-politicos

Fries, L. (2015). Columna de opinión: verdad y justicia para las víctimas de prisión politica y tortura. Instituto Nacional de Derechos Humanos. Recuperado de http://www.indh.cl/columna-de-opinion-verdad-y-justicia-para-las-victimasde-prision-politica-y-tortura

Fundación Acción Pro Paz. (1966) Pacto Internacional de Derechos Económicos, Sociales y Culturales. Recuperado de http://www. derechoshumanos.net/normativa/normas/1966PactoDer echosEconomicosSocialesyCulturales.htm

Hernández, V. (2018). Mecanismos de reparación frente a violaciones a los derechos humanos establecidos por el Estado de Chile: una aproximación desde la percepción de víctimas de prisión política y tortura calificados por la Comisión Valech. Santiago de Chile: Universidad Católica Silva Henríquez. 
Instituto Nacional de Derechos Humanos. (2012). Situación de los Derechos Humanos en Chile, informe anual 2012. Chile: INDH.

Instituto Nacional de Derechos Humanos. (2014). (2a ed.). Informe de Derechos Humanos para Estudiantes. Santiago de Chile.

Jelin, E. (2002). (2a ed.) Los trabajos de la memoria. Madrid, España: Editorial Siglo XXI de España editores S.A.

Lira, E. y Castillo, M. I. (1993). Trauma Político y Memoria Social. Psicología Política. Instituto Latinoamericano de Salud Mental y Derechos Humanos, 6(98), 95-116. Recuperado de https://www.uv.es/garzon/psicologia\%20politic/N6-5.pdf

Lira, E. y Loveman, B. (2005). Políticas de reparación, Chile 1990-2004. Santiago de Chile: LOM/DIBAM.

Naciones Unidas. (1948). Declaración Universal de los Derechos Humanos. Recuperado de http://www.un.org/es/universal-declarationhuman-rights/ 